\title{
Direct Analysis of Steels by Inductively Coupled Plasma Emission Spectrometry with a Q-Switched Neodymium:YAG Laser
}

\author{
Tadashi Mochizuki, Akiko Sakashita, Takanori AkIYoshI and Hideo Iwata \\ Analysis Research Department, Advanced Technology Research Center, NKK Corporation, \\ Mimamiwatarida, Kawasaki 210, Japan
}

\begin{abstract}
A laser ablation system using a cw Q-switched Nd:YAG laser has been developed for the direct analysis of steels by inductively coupled plasma emission spectrometry (ICP-AES). The YAG laser used for this work produced fine particles (particle size, $<0.2 \mu \mathrm{m}$ ). The amount of particles obtained by ablating pure iron for $20 \mathrm{~s}$ was about $400 \mu \mathrm{g}$. The ablated samples were directly introduced into the plasma. The horizontal movement of sample during laser firing prevented the laser beam from becoming out of focus on the sample surfaces, and that was effective to improve sensitivity and precision. Variation in the amount of the particles ablated at each analysis impaired analytical precision; consequently, the matrix element of iron was used as the internal standard. The precision(RSDs, \%) values for seven elements in steel were $0.3-1.6 \%$. Detection limits ranged from $2 \mathrm{ppm}$ for $\mathrm{Ni}, \mathrm{Cr}$ and $\mathrm{Cu}$ to $87 \mathrm{ppm}$ for Si.
\end{abstract}

Keywords Laser ablation method, inductively coupled plasma emission spectrometry, Q-switched neodymium: YAG laser, steel

The laser ablation technique has been successfully applied to the direct inductively coupled plasma emission spectrometric analysis (ICP-AES) of metals and powder materials of industrial origin. ${ }^{1-6}$ The laser ablation method provides unique advantages over other types of solid sample introduction methods: i.e., the ability to analyze both conductive and nonconductive solid samples, little or no sample preparation, short analysis time and the small amounts of samples required.

We have been exploring the applications of the laser ablation method for ICP-AES ${ }^{5,6}$ and ICP-MS ${ }^{7}$ in the direct elemental analyses of industrial samples. However, the $1 \mathrm{~J}$ ruby laser used for ablating solids limited precision and power of detection, because of the small evaporated amount of samples, the low pulse repetition rate and the low homogeneity in solid state for some elements tested. Ishizuka and Uwamino ${ }^{3}$ showed that using a high power ruby laser in normal mode, relatively large amounts of particles could be obtained, which would yield excellent detection limits. But the use of the laser system was not effective for improvement in precision. Therefore, this work was undertaken to develop the precise laser ablation technique for the direct analysis of steel samples. The analytical system using a cw Q-switched Nd:YAG laser, which fires a laser beam of low energy at the high pulse repetition rate of $1 \mathrm{kHz}$, has been established. The proposed system permits excellent precision as well as high sensitivity.

\section{Experimental}

\section{Instrumentation}

The laser ablation/ICP-AES system used for this work was the same as described previously, except for the Nd:YAG laser. ${ }^{5,6}$ The experimental facilities and operating conditions of the system are listed in Table 1. A cw-Nd: YAG laser (NEC, Shiba, Tokyo) was used in the Q-switched mode for ablating solids; it was operated at maximum energy to achieve high sensitivity. The reproducibility of the energy of the laser beam is $\pm 1.1 \%$ under the operating conditions used. A schematic diagram of the laser ablation device is shown in Fig. 1. Both the ablation chamber and samples are mounted on a three-axis translation stage. The vertical axis $(Z)$ is manually adjustable to focus the laser beam on the sample surface. The horizontal axis $(X)$ is driven by a stepper motor, and the samples are continuously translated at a movement speed of up to $35 \mathrm{~mm} \mathrm{~min}^{-1}$. The $1 \mathrm{~J}$ ruby laser for Laser Microanalyzer LMA-10 (Carl Zeiss Jena) was used for reference. ${ }^{5,6}$ It was operated at the maximum energy to ablate the largest amount of particles: this amount was about $1 \mu \mathrm{g}$ for steels. $^{6}$

An ICP emission spectrometer, Model JY-48P (Seiko Instruments Inc., Kameido, Tokyo) was used 
Table I Experimental facilities and operating conditions of the laser ablation/ICP-AES analytical system

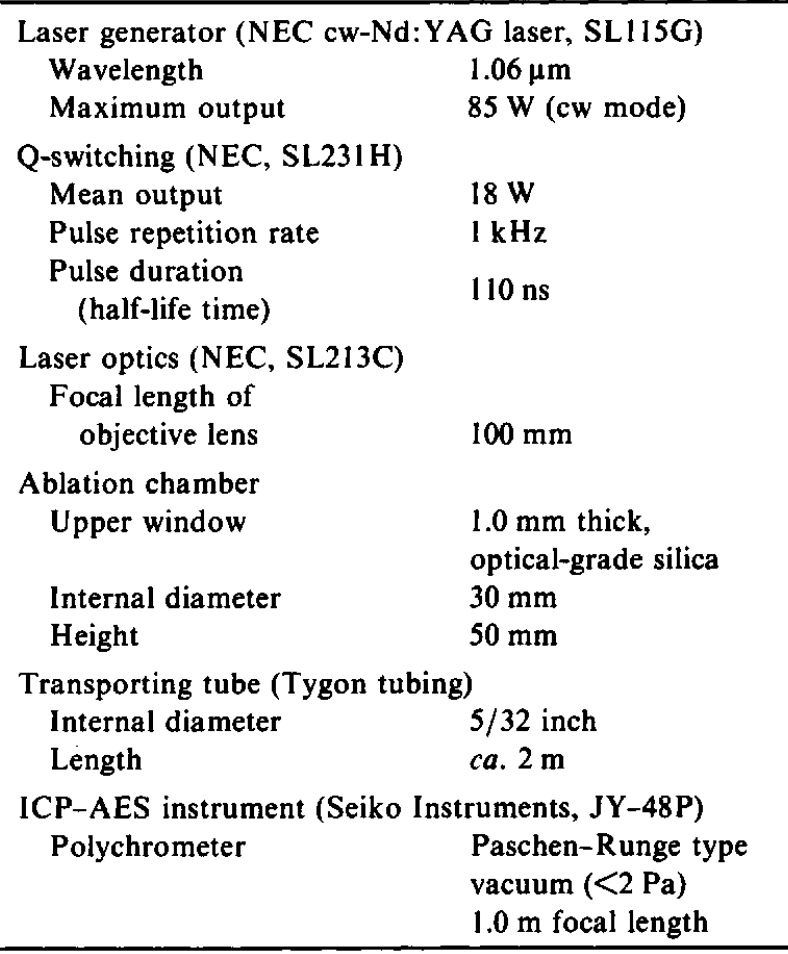

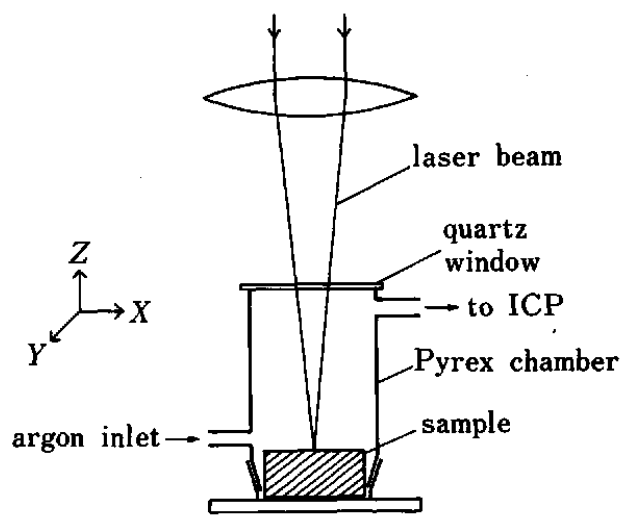

Fig. 1 Schematic diagram of the laser ablation device.

with a Paschen-Runge vacuum polychrometer. The instrumental settings for the analysis of steels are the same as described in the previous paper. ${ }^{6}$ The ICP was operated at the same conditions as used for the solution introduction method except for the observation height.

\section{Procedure}

A steel sample is set in the laser ablation chamber and the chamber is set below an objective lens of the laser optics. The laser is focussed on the sample surface. The laser pulses are fired for $20 \mathrm{~s}$ at the pulse repetition rate of $1 \mathrm{kHz}$. During laser firing, the sample is horizontally moved at the speed of $35 \mathrm{~mm} \mathrm{~min}^{-1}$ in order to keep the focus on the sample surface. The crater diameter was about $0.2 \mathrm{~mm}$ for steels. The particles produced are introduced into the plasma by the flow of argon carrier gas. The measurement of emission intensities is started just before laser firing and the intensities are integrated for $50 \mathrm{~s}$. Background values obtained from the plasma with no laser pulses are subtracted from the intensity data obtained.

The block-form steels are polished with a piece of 100-mesh alumina paper to obtain the flat surfaces of samples; the surfaces are washed with alcohol prior to analysis.

\section{Samples}

The steels used for the investigation are JSS (Japanese Industrial Standards of Iron and Steel) standard reference materials and the domestic pure iron (99.98\% grade).

\section{Results and Discussion}

\section{Time-resolved output}

When successive laser shots are fired onto the same position of the sample surface, the response obtained gradually decreases with time. ${ }^{2}$ That is because the laser beam becomes out of focus on the surface as the number of laser shots increases. In this work, the samples were horizontally moved during laser firing to keep the focus on the sample surfaces. The effect of a sample movement speed on the time-resolved output of $\mathrm{Mn}$ in the JSS163-4 steel standard is shown in Fig. 2. The steady-state levels were produced at the sample speeds of $15-35 \mathrm{~mm} \mathrm{~min}^{-1}$. However, the use of the higher speed yielded larger amounts of the particles to improve sensitivity. Kawaguchi et al. ${ }^{2}$ in a report on the laser ablation/ICP-AES indicated that, using the

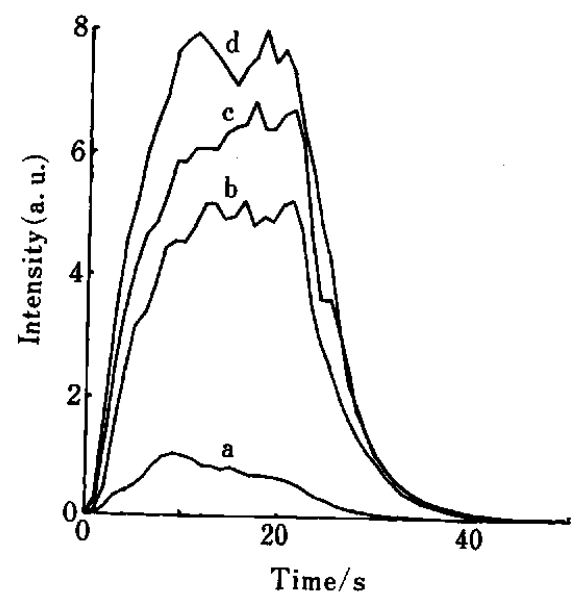

Fig. 2 Effect of the sample movement speed on time-resolved output of Mn in JSS163-4 standard steel (Mn content, $0.46 \%$ ). The laser was fired for $20 \mathrm{~s}$ at the pulse repetition rate of $1 \mathrm{kHz}$. Sample movement speed $\left(\mathrm{mm} \mathrm{min}^{-1}\right): 0$ (a); 15 (b); 28 (c); 35 (d). 


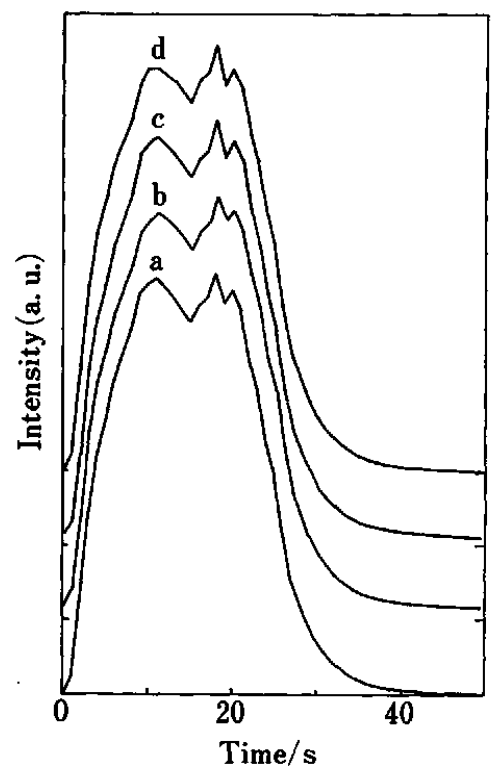

Fig. 3 Time-resolved outputs of $\mathrm{Ni}(\mathrm{a}), \mathrm{Cr}(\mathrm{b}), \mathrm{Cu}$ (c) and $\mathrm{Fe}(\mathrm{d})$ obtained by analyzing JSS163 standard steel. The laser was fired for $20 \mathrm{~s}$ at the pulse repetition rate of $1 \mathrm{kHz}$ and the steel was horizontally moved at the speed of $35 \mathrm{~mm} \mathrm{~min}^{-1}$ during laser firing.

multi-pulse mode, the shape of time-resolved outputs was different from element to element because of the fractional vaporization in the ablation process. Figure 3 shows the signals for $\mathrm{Ni}, \mathrm{Cr}, \mathrm{Cu}$ and $\mathrm{Fe}$ obtained at the sample movement speed of $35 \mathrm{~mm} \mathrm{~min}^{-1}$. There was no significant difference in the trend of the curves for all elements tested at the movement speeds of 15$35 \mathrm{~mm} \mathrm{~min}{ }^{-1}$. However, the absence of sample translation yielded the differences in time-resolved profiles for the elements tested, because of the fractional vaporization. The facts indicate that the movement of samples reduces the measurement error arising from the fractional vaporization and that the internal standard method is effective for the improvement of precision. ${ }^{1,6}$ A maximum movement speed of $35 \mathrm{~mm} \mathrm{~min}^{-1}$ was therefore used for the analysis of steels.

\section{Particles}

The ablated amount of the samples was measured by collecting the material on a membrane filter (pore size; $0.2 \mu \mathrm{m}$ ), followed by determining the iron by ICPAES. ${ }^{6}$ The amount increased with increasing pulse energy. About $400 \mu \mathrm{g}$ of the particles were obtained by ablating pure iron for $20 \mathrm{~s}$ with maximum laser pulse energy. The ablation rate of $20 \mathrm{ng}$ pulse $^{-1}$ for the YAG laser used was low in comparison with those of $1-30 \mu \mathrm{g}$ puls $^{-1}$ for other types of lasers reported..$^{1-3,6}$ That is mainly due to the low energy of the YAG laser used. However, a high pulse repetition rate yielded a relatively large total amount of the particles in a given integration period.

The rather large particles tend to remain within the transporting tube. So, the shape and size of the particles ablated have a great influence on the precision of the laser ablation/ICP-AES. Scanning electron micrographs of the particles collected on the filter indicate that the majority of the particles were fibrous in shape and that the fibers consist of fine particles (particle size $<0.2 \mu \mathrm{m}$ ). The previous work ${ }^{8}$ on the laser evaporation showed that the pulsed YAG laser produced the fine particles and that the particles were arranged in a row to yield the chain structure. The results indicate that the fibers obtained by using $\mathrm{cW}$ YAG laser are mainly formed in the particle translation process or the particle collection process. Consequently, the particles ablated from steels by the YAG laser used are small enough to be directly introduced into the plasma. Therefore, the laser was operated at the maximum energy to obtain high sensitivity.

\section{Precision and detection limits}

The laser ablation/ICP-AES described here was applied to the direct analysis of steel samples. Precision data for the measurement of the JSS163-4 steel standard is shown in Table 2, together with those obtained by the analytical system using the ruby laser. In the YAG laser system, the use of iron as an internal standard provides better precision for all elements listed in Table 2. The precision ranged from $0.3 \%$ to $1.6 \%$ for the YAG laser system. Although a small amount of solid samples is introduced into the ICP in the laser ablation method, the precision data obtained are comparable to those obtained by the conventional solution introduction method. On the other hand, the precision ranged from $1.0 \%$ to $11.5 \%$ for the ruby laser system. Consequently, the use of the cw Q-switched YAG laser greatly improved precision for the direct analysis of steels. This is mainly because the larger

Table 2 Relative standard deviations (RSDs $\left.{ }^{\mathrm{a}}, \%\right)$ of intensities or intensity ratios for the analysis of the JSS $163-4$ steel standard

\begin{tabular}{|c|c|c|c|c|}
\hline \multirow[b]{2}{*}{ Element } & \multirow{2}{*}{$\begin{array}{c}\text { Content, } \\
\%\end{array}$} & \multicolumn{2}{|c|}{ YAG } & \multirow{2}{*}{ 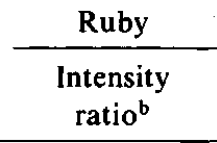 } \\
\hline & & Intensity & $\begin{array}{l}\text { Intensity } \\
\text { ratio }^{\mathrm{b}}\end{array}$ & \\
\hline $\mathrm{Si}$ & 0.22 & 6.7 & 1.6 & 6.6 \\
\hline Mn & 0.46 & 6.1 & 0.6 & 4.4 \\
\hline $\mathbf{P}$ & 0.020 & 6.2 & 0.8 & 11.5 \\
\hline $\mathbf{S}$ & 0.024 & 4.2 & 1.5 & 9.3 \\
\hline $\mathrm{Ni}$ & 0.12 & 5.8 & 0.4 & $1.0,1.1(0.73 \%)^{c}$ \\
\hline $\mathrm{Cr}$ & 0.10 & 5.8 & 0.3 & 1.2 \\
\hline $\mathrm{Cu}$ & 0.10 & 6.2 & 0.7 & 1.5 \\
\hline
\end{tabular}

a. The RSDs are based on six replicate measurements (except for c).

b. Emission intensity of Fe II $259.94 \mathrm{~nm}$ was used for the standardization of intensities measured.

c. The RSD based on ten replicate measurements was reported by Thompson et al.' The value in parentheses indicates the content in percent. 
Table 3 Detection limits $(3 \sigma, \mathrm{ppm})$ for various elements in steel

\begin{tabular}{lrrrrrr}
\hline & \multicolumn{2}{c}{ This work } & & \multicolumn{3}{c}{ Reported } \\
\cline { 2 - 3 } \cline { 6 - 7 } \cline { 5 - 6 } & YAG & Ruby & & Ref. 1 $1^{\mathrm{a}}$ & Ref. 2 ${ }^{\mathrm{b}}$ & Ref. 3 $^{\mathrm{c}}$ \\
\hline $\mathrm{Si}$ & 87 & 712 & & & \\
$\mathrm{Mn}$ & 6 & 4 & & 80 & 470 & 0.3 \\
$\mathrm{P}$ & 10 & 20 & & 10 & & \\
$\mathrm{~S}$ & 33 & 23 & & 15 & & \\
$\mathrm{Ni}$ & 2 & 8 & & 70 & 40 & 1 \\
$\mathrm{Cr}$ & 2 & 30 & & 15 & 40 & 1 \\
$\mathrm{Cu}$ & 2 & 12 & 20 & & 0.3 \\
\hline
\end{tabular}

a. The values were obtained with the system using the same ruby laser as used for this work. The laser was operated at the energy of $1 \mathrm{~J}$ and about $1 \mu \mathrm{g}$ of particles was ablated.

b. Pulse-YAG laser was used in multi-pulse mode (pulse repetition rate; $10 \mathrm{~Hz}$ ). The laser energy was $70 \mathrm{~mJ}$.

c. Ruby laser was operated at the energy of $18 \mathrm{~J}$ in normal mode and yielded about $30 \mu \mathrm{g}$ of particles.

amount of the particles obtained by the YAG laser system yields the higher count rates of emission intensities and minimizes the errors concerning with the variation in the evaporated amount at each laser pulse and the low homogeneity in solid state.

Working curves for the elements listed in Table 2 were prepared with the standard samples of JSS162-4164-4 and pure iron. There was a linear relationship between the response ratios of the analyte element to iron and the contents. The detection limit is defined as three times the standard deviations obtained by analyzing pure iron in six replicates with these curves. Table 3 shows the detection limits for various elements in steel, together with those reported elsewhere. ${ }^{1-3}$ The proposed YAG laser system yielded high sensitivity; the limits ranged from $2 \mathrm{ppm}$ for $\mathrm{Ni}, \mathrm{Cr}$ and $\mathrm{Cu}$ to $87 \mathrm{ppm}$ for $\mathrm{Si}$. However, the values were higher than those obtained by using the $18 \mathrm{~J}$ ruby laser ${ }^{3}$, mainly because of the lower ablation rate of the YAG laser used.

In conclusion, the results of this work indicate that a cw Q-switched Nd:YAG laser is suitable for direct elemental analysis of steels by the laser ablation/ICPAES method. The proposed system provided unique advantages such as excellent precision and high sensitivity. Therefore, the system is very useful for direct steel analyses on a routine basis.

\section{References}

1. M. Thompson, J. E. Goulter and F. Sieper, Analyst [London], 106, 32 (1981).

2. H. Kawaguchi, J. Xu, T. Tanaka and A. Mizuike, Bunseki Kagaku, 31, E185 (1982).

3. T. Ishizuka and Y. Uwamino, Spectrochim. Acta, 38B, 519 (1983).

4. J. W. Carr and G. Horlick, Spectrochim. Acta, 37B, 1 (1982).

5. T. Mochizuki, A. Sakashita, H. Seno and H. Iwata, Bunseki Kagaku, 37, 12 (1988).

6. T. Mochizuki, A. Sakashita and H. Iwata, Bunseki Kagaku, 37, T109 (1988).

7. T. Mochizuki, A. Sakashita, H. Iwata, T. Kagaya, T. Shimamura and P. Blair, Anal. Sci., 4, 403 (1988).

8. T. Ariyasu, A. Susuki, A. Matsunawa and S. Katayama, Rev. Laser Engineering, 15, 721 (1987).

(Received June 3, 1989) (Accepted August 7, 1989) 